\title{
Study of Traffic Flow at a Busy Intersection in Kanchipuram, India
}

\author{
R.Sumathi ${ }^{1}$ \\ ${ }^{1}$ Assistant Professor, Department of Civil and Structural Engineering, \\ Sri ChandrasekharendraSaraswathiViswaMahaVidhalaya, \\ Enathur, Kanchipuram, Tamilnadu, India. \\ Email:sumathiram72@gmail.com
}

\begin{abstract}
Traffic flow analyses are used to achieve the safe, effective and efficient movement of peoples and goods on roadways within a scheduled time are directly linked with traffic characteristics. The parameters which are deciding the traffic flows are density, speed and volume. Nowadays the density and vehicle volume becomes very high due to increase in population, drastic changes in the economics of the middle class families and also people want the sophisticated life. To improve the road infrastructure for the future, the well planned and effective management is mandatory. In this study the traffic volume at junction, which is considered as a heavy traffic area was carried out manually and the footage from CCTV were taken and the suggestions were given to regularize the traffic. The results obtained clearly stated that two wheelers and Cars take major proportion in the traffic stream flow.
\end{abstract}

Keywords: Traffic volume; density; Traffic congestion

\section{INTRODUCTION}

Bright future of the city is mainly based on its transportation. Many cities are facing various problems due to rapid industrialization and urbanization $[1,10]$. In the developing cities the numbers of private and public vehicles are to be increased but the available space for the road is not sufficient which leads to traffic congestion. One of the unbearable problem occurs in the urban areas are traffic congestion which affects the society and economy [2]. Congestion affects the free flow of vehicles which increases the journey time, accidents and makes the people getting annoyed. This traffic congestion creates a most challenging problem in all developed and developing towns or cities [3]. In most of the metropolitan cities particularly during peak hours in the morning and in the evening people find very difficult to reach their work places and their homes. They will get mental tension and also it leads to waste more amount of fuel, time and creates lot of pollution [4].The number of pedestrians crossing and the tremendous increased in the number of all type of vehicles especially cars but there is no way for extending or widening the road due to various political and land acquisition problems [5, 8]. This difficulty should be overcome by increasing the road space or diverting the traffic by considering the distance and also convenience to the public. The current work focuses the traffic characteristics in the town of Kanchipuram at one selected priority city[6,11]. Traffic flow is studied by manual methods. For better understanding of the present status of traffic flow at the junction, traffic survey is conducted with the help of the data collection, an attempt had been made to understand the traffic patterns during different time periods. Traffic control at that junction is also dependent on the traffic flow characteristics [7, 9]. Hence the results from the present study are helpful in controlling the traffic at the intersection and also in suggesting some of the remedial measures to improve the traffic safety in the region. Remedial measures such as widening the road, changing 4-lane to 6lane or by providing more public transport can be recommended based on the outcomes of the work.

\subsection{Scope of traffic volume studies}

- To identify the transport either from public or private influences the traffic system.

- To know the seasonal, daily and hourly variations in the flow of vehicles is mainly used for the future expansion of roads.

- To assess the quality of air in the particular area where the traffic is heavy.

\section{STUDY AREA}

The city of Kanchipuram $\left(12.8342^{\circ} \mathrm{N}\right.$ latitude, $79.7036^{\circ}$ E longitude, $83.2 \mathrm{~m}(273 \mathrm{ft})$ above sea level) is located in the Indian State of Tamilnadu. The city covers an area of $11.605 \mathrm{~km}^{2}$. The land around Kanchipuram is flat and slopes towards the south and east.

As Kanchipuram falls as one of the seven Tirthas (pilgrimage sites) in India, it has tourist visitors from all over the country and even world. As Kanchipuram is known for its cultural heritage, tourism is greater here.

\section{MATERIALS AND METHODS}

For determining the study area, traffic survey was done by obtaining CCTV Footages from Kanchipuram Control Room. MoongilMandapam is one of the great junctions in kanchipuram town. CCTV footage of one camera that is for road going from MoongilMandapamto Collectrate was studied 


\section{E-ISSN: 2321-9637}

Available online at www.ijrat.org

and the vehicles passing were noted down by segregating them as Buses, Cars, Truck/Tempo, Two-wheelers by using the software Smart Traffic Analyser, (Fig.2).

CCTV Camera Footages of MoongilMandapam was obtained for one week that is from $24^{\text {th }}$ February 2017 to $2^{\text {nd }}$ March 2017 from morning 4.00 a.m to 12.00 a.m. (Table.1).The timing of footage for each day in week was classified as 4.00 $-8.00,8.01-12.00,12.01-16.00,16.01-20.00$, 20.01 - 24.00.Heavy Traffic, from the CCTV footages collected from the Control room, we can

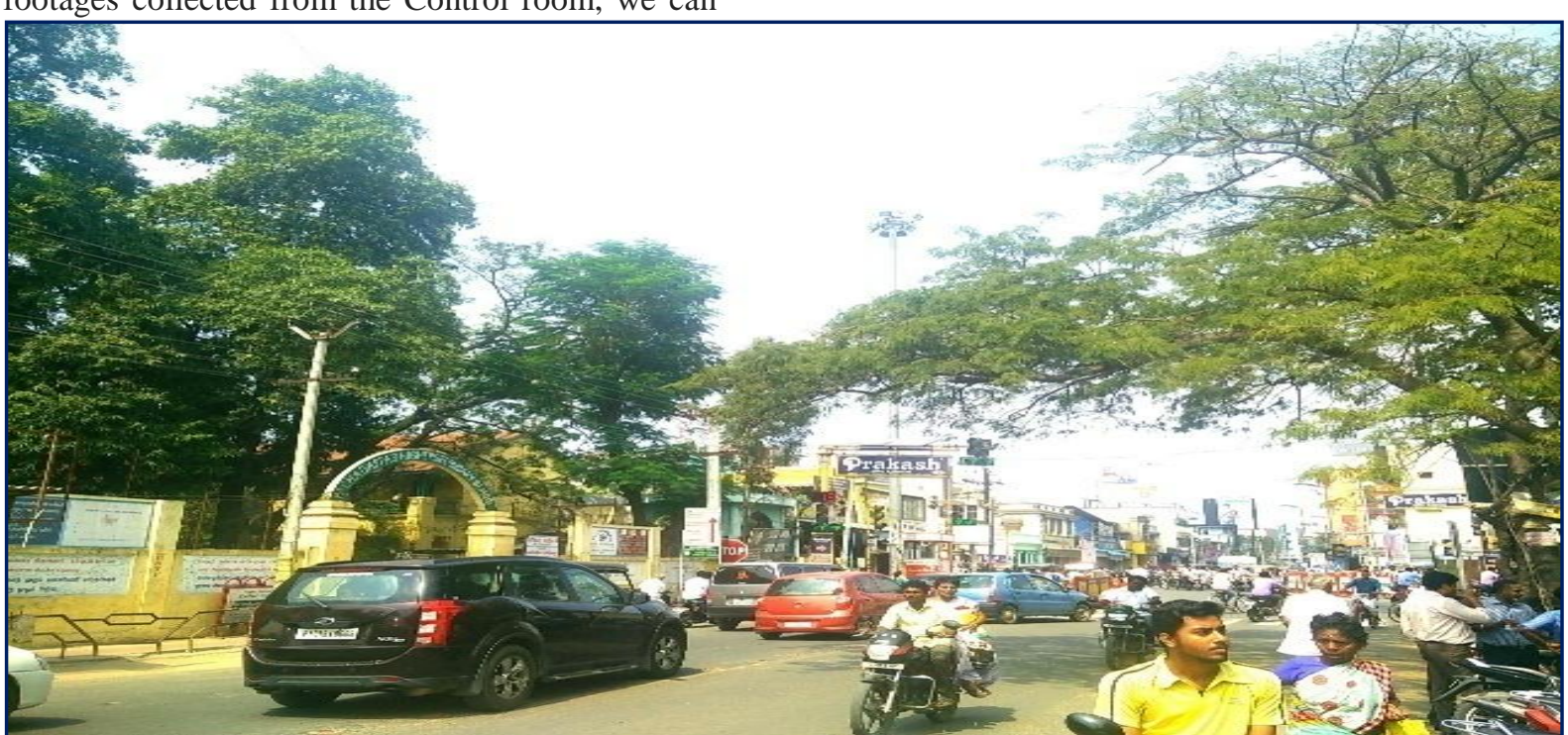

Fig.1. Study area- MoongilMandapam
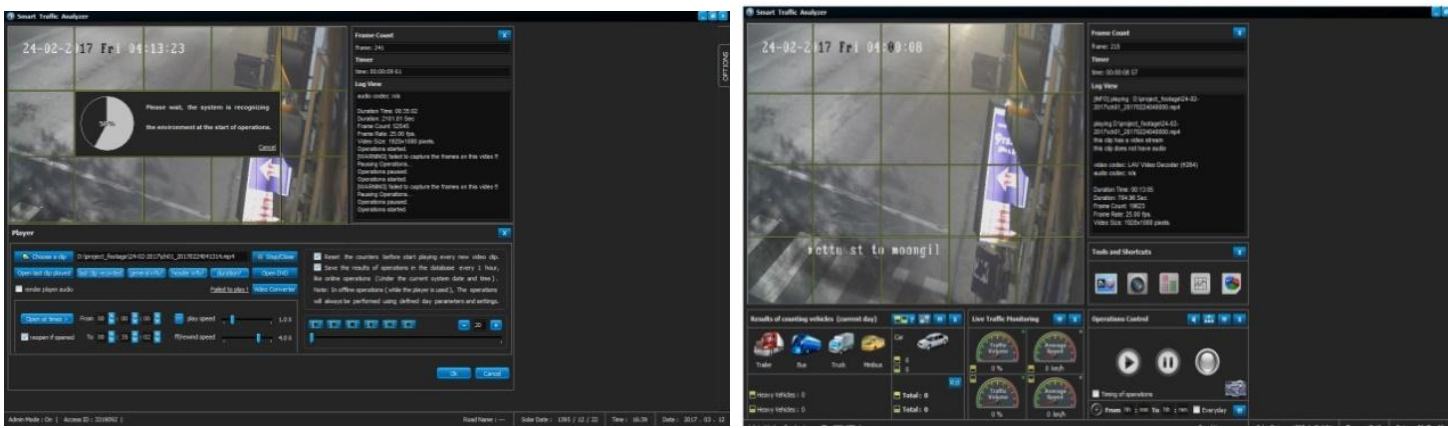

Fig.2. Screenshots of STA (SMART TRAFFIC ANALYSER)

Table 1. Composition of traffic flow stream from 24.02.2017 to 02.03.2017

\begin{tabular}{|l|l|l|l|l|l|}
\hline Time & Bus & Car & Truck/Tempo & Two Wheeler & Total \\
\hline \multicolumn{6}{|l|}{$\mathbf{2 4}^{\text {th }}$ February 2017 } \\
\hline $4.00-8.00$ & 67 & 365 & 40 & 986 & 1458 \\
\hline $8.01-12.00$ & 102 & 458 & 69 & 1051 & 1680 \\
\hline $12.01-16.00$ & 97 & 345 & 58 & 992 & 1492 \\
\hline $16.01-20.00$ & 124 & 559 & 78 & 1089 & 1850 \\
\hline $20.01-24.00$ & 129 & 576 & 64 & 1032 & 1801 \\
\hline
\end{tabular}


International Journal of Research in Advent Technology, Vol.7, No.4, April 2019 E-ISSN: 2321-9637

Available online at www.ijrat.org

\begin{tabular}{|c|c|c|c|c|c|}
\hline Total & 519 & 2303 & 309 & 5150 & 8281 \\
\hline \multicolumn{6}{|c|}{$25^{\text {th }}$ February 2017} \\
\hline $4.00-8.00$ & 64 & 357 & 43 & 999 & 1463 \\
\hline $8.01-12.00$ & 108 & 442 & 65 & 1109 & 1724 \\
\hline $12.01-16.00$ & 94 & 365 & 61 & 1033 & 1553 \\
\hline $16.01-20.00$ & 147 & 541 & 74 & 1078 & 1840 \\
\hline $20.01-24.00$ & 115 & 589 & 58 & 1156 & 1918 \\
\hline Total & 528 & 2294 & 301 & 5375 & 8498 \\
\hline \multicolumn{6}{|c|}{$26^{\text {th }}$ February 2017} \\
\hline $4.00-8.00$ & 63 & 364 & 54 & 987 & 1468 \\
\hline $8.01-12.00$ & 104 & 435 & 75 & 1125 & 1739 \\
\hline $12.01-16.00$ & 100 & 365 & 68 & 1047 & 1580 \\
\hline $16.01-20.00$ & 158 & 536 & 84 & 1185 & 1963 \\
\hline $20.01-24.00$ & 125 & 594 & 60 & 1598 & 2377 \\
\hline Total & 550 & 2294 & 341 & 5942 & 9127 \\
\hline \multicolumn{6}{|c|}{$27^{\text {th }}$ February 2017} \\
\hline $4.00-8.00$ & 72 & 389 & 60 & 997 & 1518 \\
\hline $8.01-12.00$ & 145 & 569 & 75 & 1689 & 2478 \\
\hline $12.01-16.00$ & 122 & 487 & 78 & 1165 & 1852 \\
\hline $16.01-20.00$ & 168 & 635 & 93 & 1285 & 2181 \\
\hline $20.01-24.00$ & 132 & 587 & 65 & 1635 & 2419 \\
\hline Total & 639 & 2667 & 371 & 6771 & 10448 \\
\hline \multicolumn{6}{|c|}{$28^{\text {th }}$ February 2017} \\
\hline $4.00-8.00$ & 74 & 395 & 63 & 845 & 1377 \\
\hline $8.01-12.00$ & 154 & 615 & 78 & 1745 & 2592 \\
\hline $12.01-16.00$ & 136 & 565 & 82 & 1365 & 2148 \\
\hline $16.01-20.00$ & 189 & 645 & 96 & 1278 & 2208 \\
\hline
\end{tabular}


International Journal of Research in Advent Technology, Vol.7, No.4, April 2019 E-ISSN: 2321-9637

Available online at www.ijrat.org

\begin{tabular}{|c|c|c|c|c|c|}
\hline $20.01-24.00$ & 145 & 591 & 74 & 1784 & 2594 \\
\hline Total & 698 & 2811 & 393 & 7017 & 10919 \\
\hline \multicolumn{6}{|c|}{$1^{\text {st }}$ March 2017} \\
\hline $4.00-8.00$ & 85 & 345 & 54 & 749 & 1233 \\
\hline $8.01-12.00$ & 185 & 641 & 85 & 2846 & 3757 \\
\hline $12.01-16.00$ & 147 & 558 & 94 & 1623 & 2422 \\
\hline $16.01-20.00$ & 173 & 628 & 61 & 2574 & 3436 \\
\hline $20.01-24.00$ & 138 & 586 & 83 & 2145 & 2952 \\
\hline Total & 728 & 2758 & 377 & 9937 & 13800 \\
\hline \multicolumn{6}{|c|}{$2^{\text {nd }}$ March 2017} \\
\hline $4.00-8.00$ & 87 & 389 & 51 & 689 & 1216 \\
\hline $8.01-12.00$ & 245 & 784 & 84 & 2745 & 3858 \\
\hline $12.01-16.00$ & 214 & 641 & 94 & 1783 & 2732 \\
\hline $16.01-20.00$ & 229 & 662 & 65 & 2687 & 3643 \\
\hline $20.01-24.00$ & 185 & 587 & 90 & 2055 & 2917 \\
\hline Total & 960 & 3063 & 384 & 9959 & 14366 \\
\hline
\end{tabular}

\subsubsection{7}

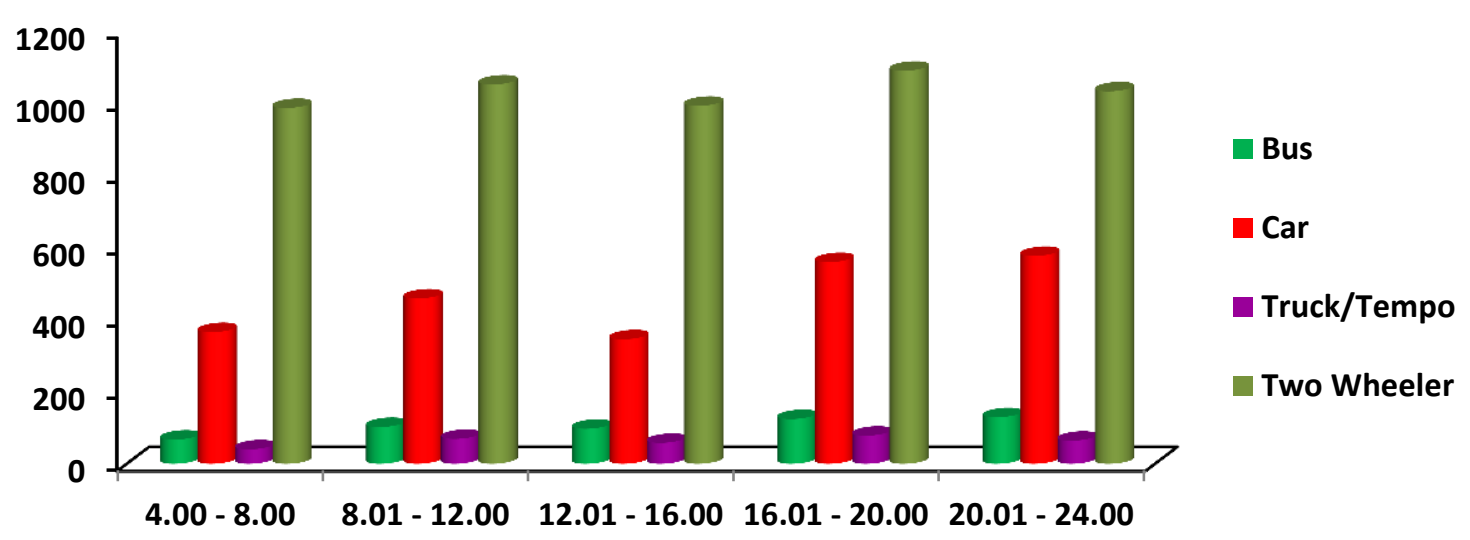


International Journal of Research in Advent Technology, Vol.7, No.4, April 2019

E-ISSN: 2321-9637

Available online at www.ijrat.org

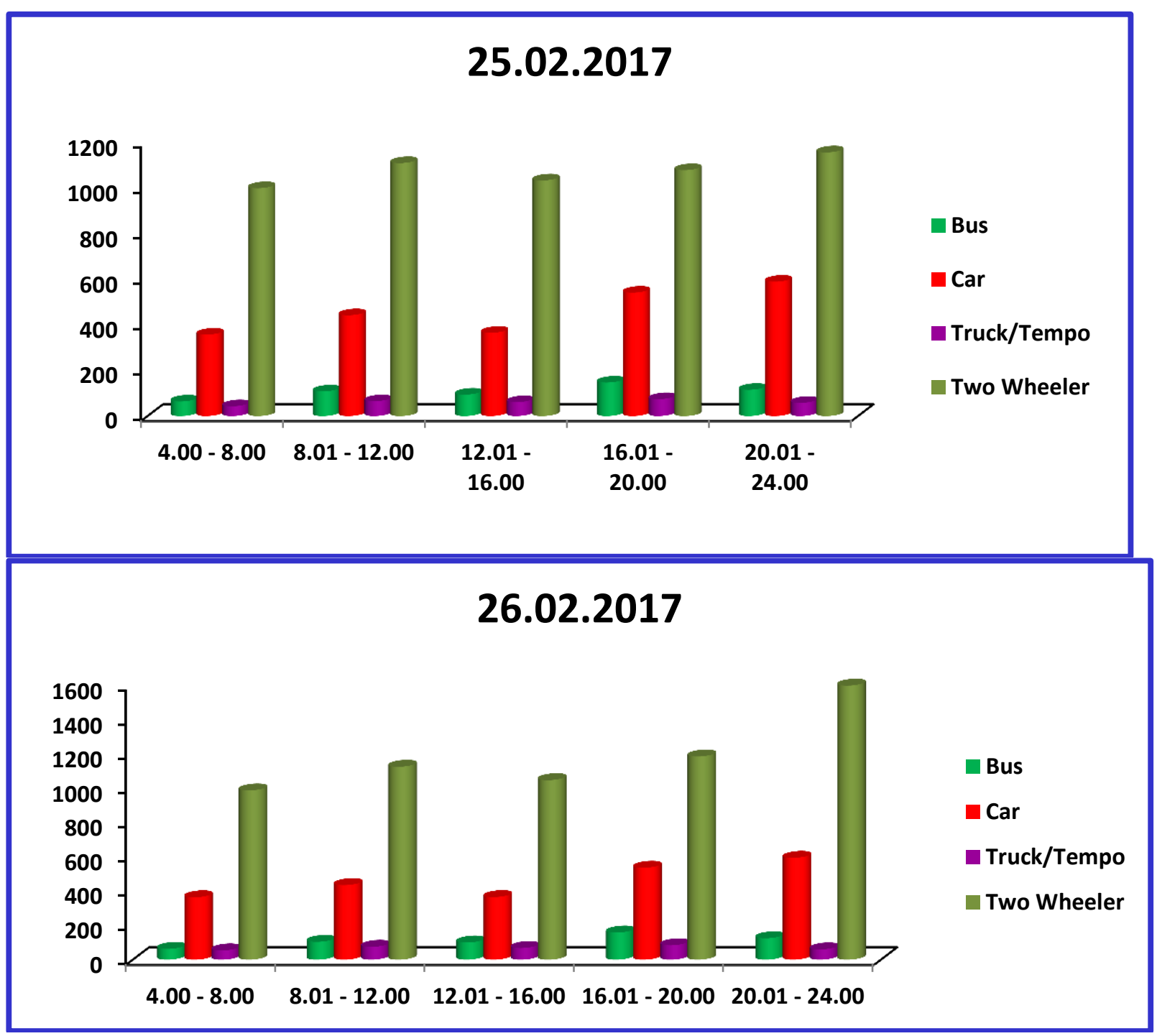


International Journal of Research in Advent Technology, Vol.7, No.4, April 2019

E-ISSN: 2321-9637

Available online at www.ijrat.org

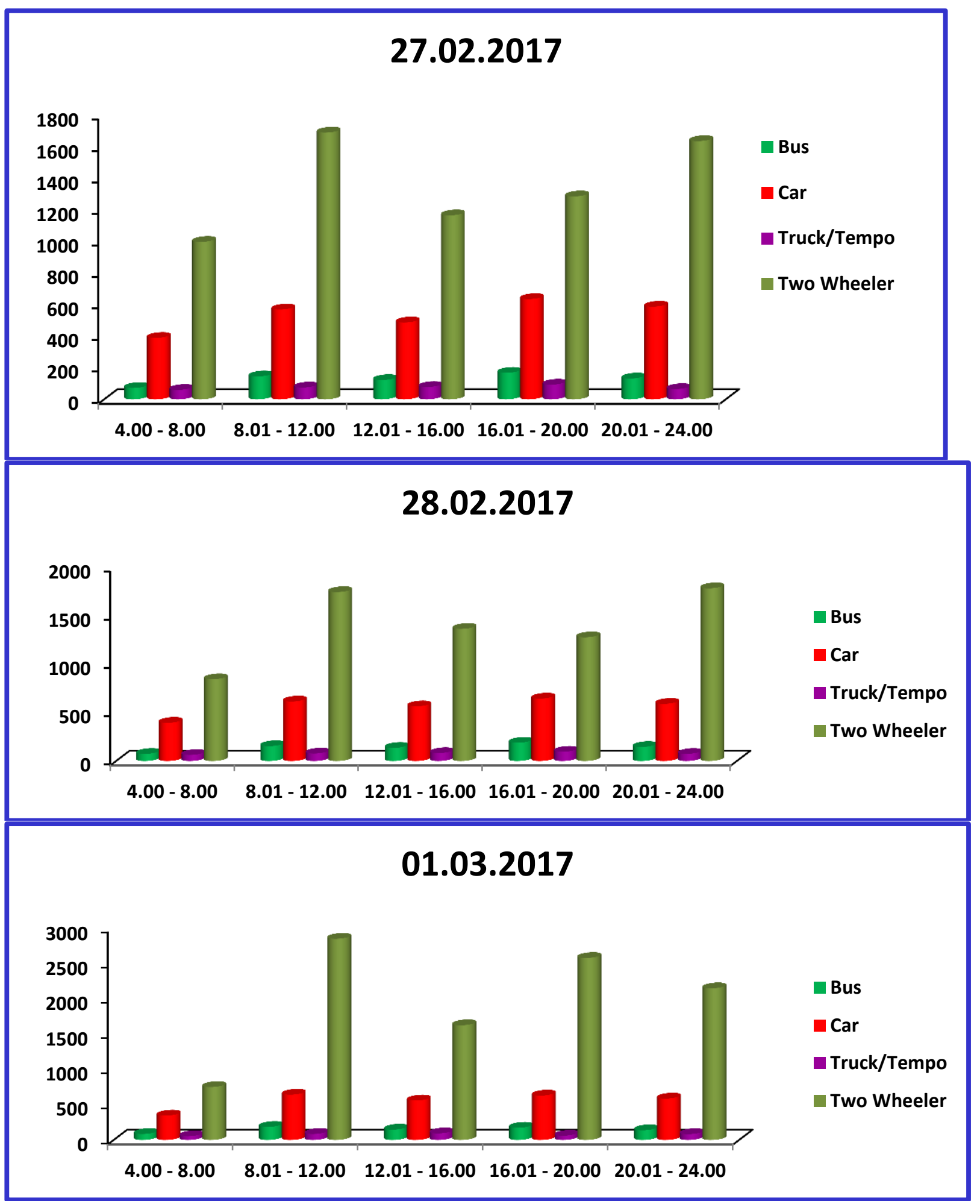




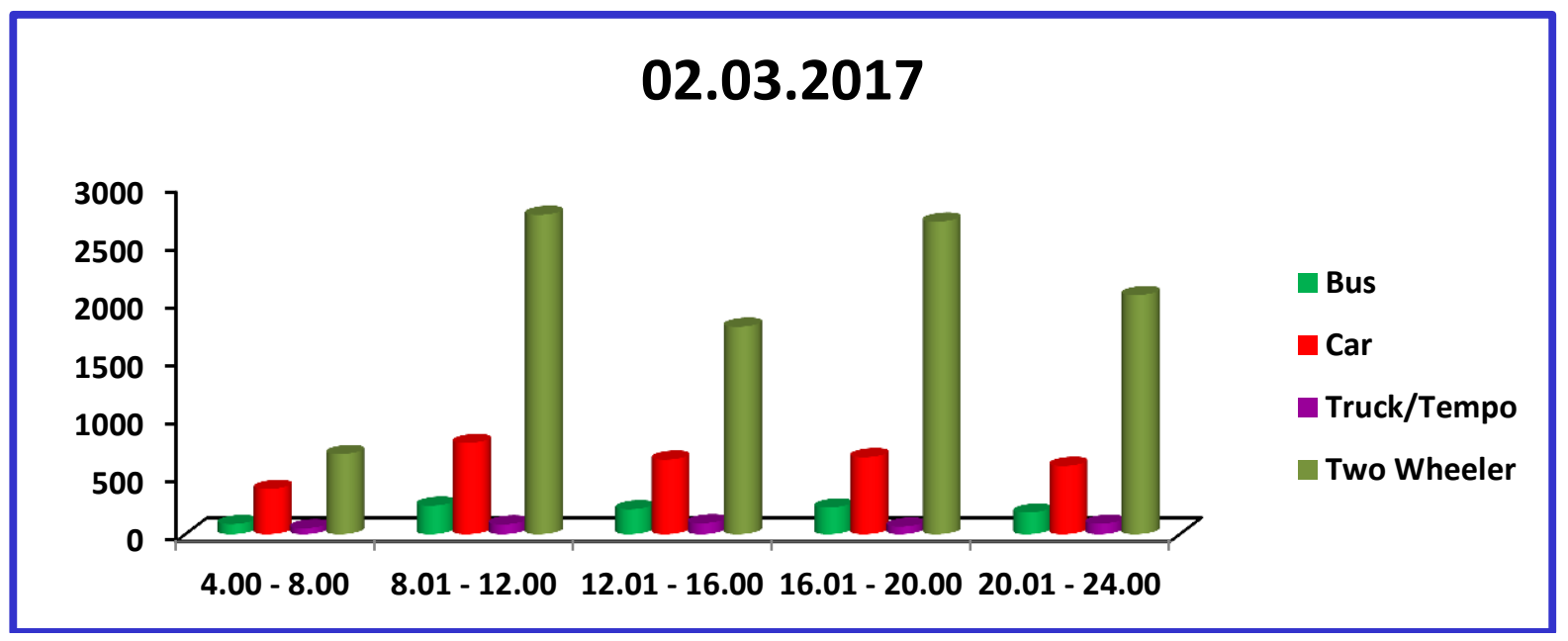

\section{RESULTS AND DISCUSSIONS}

The results shown that the number of vehicles passed that junction during week days were higher than weekends. The density of traffic was high during peak hours in the morning and in the evening hours.(8.01 a.m. -12.00 p.m and 4.00p.m8.00 p.m.). In the composition of traffic stream flow the two wheelers are in higher density than other mode of vehicles.

\section{CONCLUSION}

Vehicle composition shows that two wheelers were in major proportion compared to other vehicles. The two wheelers occupied $60 \%$ in the total number of vehicles. The reason for this were most of the people are using two wheelers immaterial of their status and it occupied less space. It is very comfortable and convenient for the people during traffic jam. The results were clearly indicated that the number of cars passing through the junction is considerably increased than any other mode of vehicles due to the economic status of the people and it is the main junction to reach most of the important towns. While comparing the type of vehicles per day $20 \%$ was taken by cars from the total number of vehicles. This study clearly stated that it is better way to make it as one way or widening of the junction. The second alternative what we suggested will take some time to clear all the issues, the immediate way to solve the problem is to make alternate routes and divert the traffic stream.

\section{REFERENCES}

[1] M. Darbari, M.;Srivastava, A. K.;Medhavi, S.; (2008) Emperical Analysis of Urban Traffic System of Lucknow Using Data Modeling and Capturing Technique.Serbian Journal of Management, 3 (2), pp.145 - 156.

[2] Sitesh Kumar Singh; AnkitBansal;(2016) Multimodal Interpretation and Analysis of Traffic Survey Data.International Journal of Innovative
Research in Science, Engineering and Technology, 5(5), pp. 7040-7048

[3] Mohammad RafayetHossain; Md. ShakhawatHossenand Roxana Hafiz;(2013) Traffic Impact Analysis of RE-Shedulin Educational Institutes A Case Study of Dhanmondi Residential Area, Dhaka. International Journal of Sustainable Land Use and Urban Planning,1(2), pp. $1-15$.

[4] Ramesh Kumar, G.B.; Priyarakshitha, K.R.; (2018), Traffic Congestion Study with A Reality Approach-A Review. International Journal of Pure and Applied Mathematics, 119 (17), pp. 10611069.

[5] Jung-Ah Ha;Ju-Sam Oh; (2014) Estimating Annual Average Daily Traffic Using Daily Adjustment Factor. Journal of Emerging Trends in Computing and Information Sciences,5(7), pp. 580587

[6] Md. AhsanHabib; AnikaNowshinMowrin; BerjeesAnisalkra; (2018) Analysis of Capacity Volume Study of Selected Highway of Bangladesh. IJARIIE, 4(3), pp.366-375

[7] Breeten Singh Konthoujam; Rajashekara, M. R.; (2015) A Study on Urban Road Widening Project based on Prediction of Level of Service (LOS) - A Case Study in Banerghatta Road Banagalore. International Journal of Engineering Research \& Technology,4(6), pp. 1176-1179

[8] SougataMaji;(2017) Traffic Congestion And Possible Solutions A Case Study of Asansol. Journal of Research in Humanities and Social Science,5(9), pp. $42-46$.

[9] Mohanra, E. K.; Geetha, A.; Jeevitha, A.; Kokila, M.; Impacts of road safety initiatives, International Journal of Intellectual Advancements and Research in Engineering Computations, 5(1), pp. 940-945

[10] Milan Pandya; NikhilRaval;(2015) Development of Speed - Density Relationship for the Urban Area - A Case Study of Ahmedabad City. International Journal for Scientific Research \& Development, 3(5), pp.41-43 
International Journal of Research in Advent Technology, Vol.7, No.4, April 2019

E-ISSN: 2321-9637

Available online at www.ijrat.org

[11] Shreeshail A Policepatil; Vishal;Roopa; Suresh;Shrishail;Inganakal, S.K; (2018) Traffic Volume Study of Kalaburagi, Karnataka. International Research Journal of Engineering and Technology, 5(6), pp.1925-1929 